\title{
RESEARCH ON STABILITY OF OPENING SECTION AT BAYMOUTH BREAKWATER
}

\author{
Junichiro SAKUNAKA ${ }^{1}$ and Taro ARIKAWA ${ }^{2}$
}

\begin{abstract}
The baymouth breakwater is to protect the port area from tsunami. It narrows the bay mouth and prevents tsunami from flowing in the port area. A submerged breakwater is built at the central opening section of the baymouth breakwater (Tsunami breakwater) to close the bay mouth as much as possible. Because of narrowness, it is expected strong current is generated at the opening section of the breakwater when tsunami occurs. The purpose of this study is to examine the stability of the opening of the breakwater on the basis of the result of numerical wave tank. Thus, conducting the experiments of the stability of the opening of the breakwater in large flume confirms the validity of results of calculations.
\end{abstract}

Keywords: submerged breakwater; stability of sliding; CADMAS-SURF/3D

\section{INTRODUCTION}

A baymouth breakwater constructed for the purpose of preventing or restricting a tsunami from reaching the shore does so by restricting the flow of the tsunami by narrowing the opening of the bay mouth. Submerged breakwaters are commonly installed along with bay mouth breakwaters to further narrow the opening. However, a significant restriction of the mouth area of a bay is likely to cause a strong current during a tsunami event. Thus, the mouth area must prove stable against these currents.

Iwasaki et al. (1984) and Tanimoto et al. (1988) conducted research into the stability of submerged breakwaters at the mouth area. The fluid dynamic forces acting on these submerged breakwaters were experimentally obtained, and as a result, the pressure coefficients that can be used to calculate these forces were presented. Tanimoto et al. (1988) validated the calculated pressure coefficients through a sliding experiment. In these studies, the evaluation criteria for the stability of submerged breakwaters against sliding were proposed on the basis of the experimental results. However, through numerical calculations, one can calculate the velocity and pressure at any location, and therefore, a more detailed verification of the mechanics of the stability of submerged breakwaters becomes possible.

The objective of this study is to determine the stability of a bay mouth breakwater through numerical calculations. To calculate the flow and vortices in the vicinity of the submerged breakwater heads, a three-dimensional numerical wave flume (CADMA-SURF/3D, hereinafter "CS3D") developed by Arikawa et al. (2005) is used. The stability of submerged breakwaters against sliding is evaluated by calculating the flow field around the mouth area. To validate the numerical calculations, a bay mouth model is constructed in a large-scale flume, and flows that emulate a tsunami are created. The model enables the measurement of the flow field around the mouth and the fluid dynamic forces acting on a submerged breakwater. In addition, sliding experiments on submerged breakwaters are performed.

\section{EXPERIMENTAL and CALCULATION CONDITIONS}

Test Facility

The experiments were conducted at the Wide-deep Hybrid Wave Flume (50 m long, $10 \mathrm{~m}$ wide and $4.5 \mathrm{~m}$ high, see Fig. 1). The facility has a current generator and a wave generator; hence, steady flow generation and wave generation are possible.

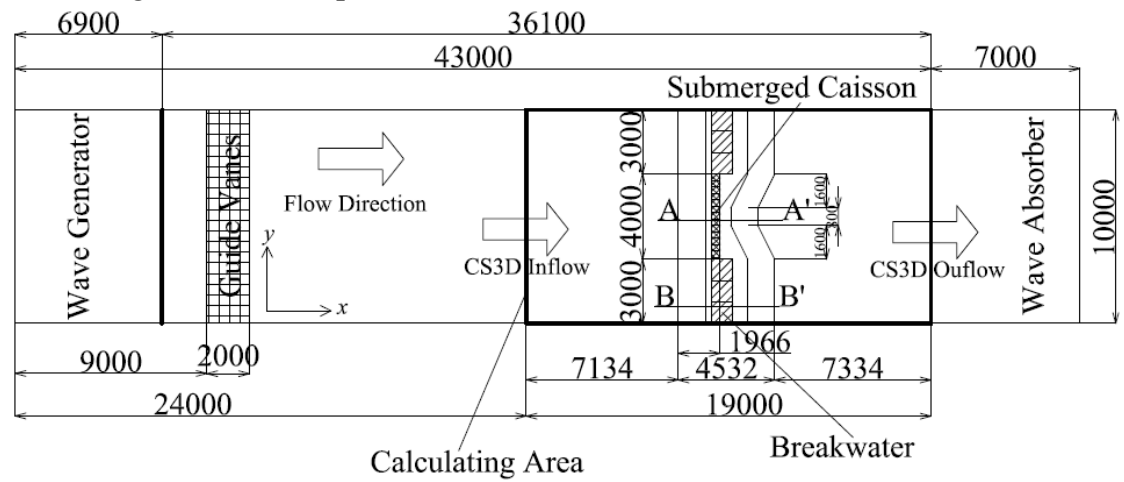

Figure 1. Plan View Drawing of the Flume (unit: $\mathrm{mm}$ ).

\footnotetext{
${ }^{1}$ Chubu Regional Bureau, Ministry of Land, Infrastructure and Transport, 2 tsukigi cho, Minato ku, Nagoya, Aichi, 460-8514, Japan

${ }^{2}$ Coastal and Ocean Engineering Field, Port and Airport Research Institute, 3-1-1 Nagase, Yokosuka, Kanagawa, 239-0826, Japan
} 
The flume consists of two layers: the upper channel and circulating channel. An axial flow pump located between the two layers generates a circulating flow. The circulating flow rate can be adjusted by controlling the pump drive to obtain the desired flow rate at the upper floor where the model is situated. One axial flow pump (rated output $45 \mathrm{~kW} / \mathrm{unit}$ ) is installed at every $5 \mathrm{~m}$ of the $10 \mathrm{~m}$ width, and thus, there are two pumps in total.

\section{Experimental Conditions}

As shown in Fig. 1, the tests are conducted using a cross-sectional arrangement whereby the breakwater and submerged breakwater line up. Photo 1 shows an overall view of the setup as seen from the downstream side. The mouth section consists of a rubble mound and a submerged breakwater, whereas the breakwater section consists of a rubble mound and a breakwater.

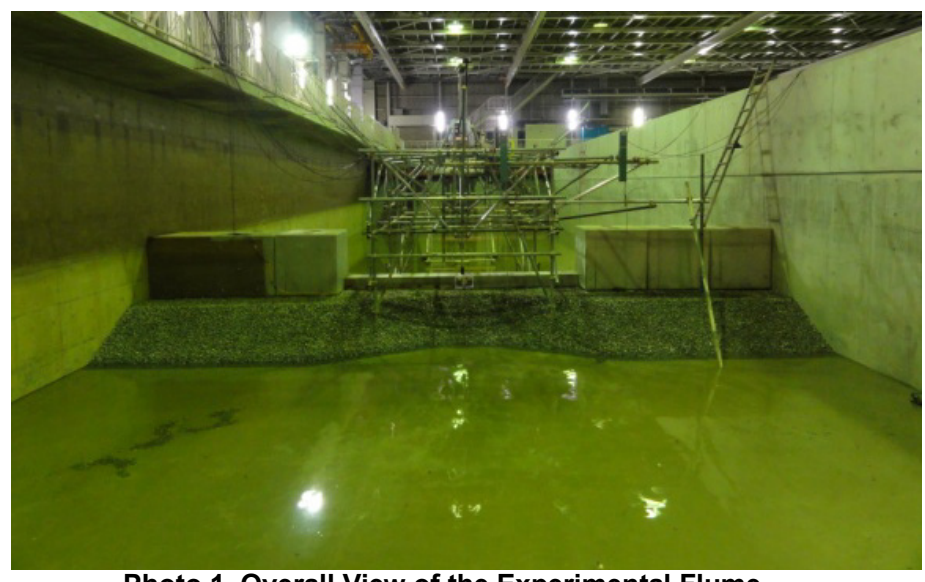

Photo 1. Overall View of the Experimental Flume.

As shown in Table 1, three submerged breakwater models with heights $0.1 \mathrm{~m}(\mathrm{AD}), 0.2 \mathrm{~m}(\mathrm{BE})$, and $0.3 \mathrm{~m}(\mathrm{CF})$ are used; moreover, 13 models of the same height are lined up at the opening for each case. The submerged breakwater models are installed at gaps of 1-2 $\mathrm{mm}$ from the side of the left-hand-side breakwater model when viewed from the upstream side. Adjuster plates with the same height as the submerged breakwater models are installed on the other end so as to block the opening, and concrete blocks are packed into the space between the plates.

\begin{tabular}{|c|c|c|c|c|}
\hline \multicolumn{5}{|c|}{ Table 1. Submerged Breakwater Model Specifications } \\
\hline Case & Height [m] & Width (perpendicular to the shoreline)[m] & Length [m] & Weight Inside Water [kN] \\
\hline AD & 0.1 & 0.4 & 0.3 & 0.153 \\
\hline BE & 0.2 & 0.4 & 0.3 & 0.306 \\
\hline CF & 0.3 & 0.6 & 0.3 & 0.688 \\
\hline
\end{tabular}

As shown in Fig. 2, the frontal normal vector is aligned to the upstream side of the breakwater. The width of the mound is set at $2.0 \mathrm{~m}$ for the breakwater and $1.2 \mathrm{~m}$ for the midsection of the submerged breakwater. Case (AD2), which has the frontal face aligned $0.45 \mathrm{~m}$ downstream of the upstream side of the breakwater, is an experiment conducted on a submerged breakwater of height $0.1 \mathrm{~m}$. Connections between sections with different mound widths are made on the downstream side. The model scale is 1/30 and Froude's law of similitude is used for the similitude calculation.
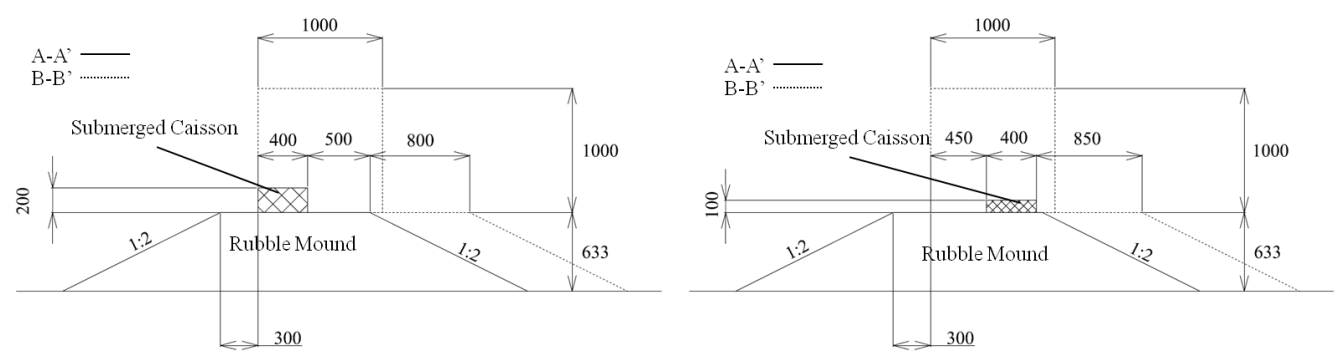

Figure 2. Cross Section of Experimental Setup (Left: BE Case, Right; AD2) (unit: $\mathbf{m m}$ ).

The water level and flow velocity at and around the mouth and the pressure acting on the submerged breakwaters are measured. Fig. 3 is a plan view drawing showing the installation locations of capacity- 
type wave gauges and electromagnetic velocimeters. WG1 through WG8 are wave gauges and V1 through $\mathrm{V} 7$ are electromagnetic velocimeters.

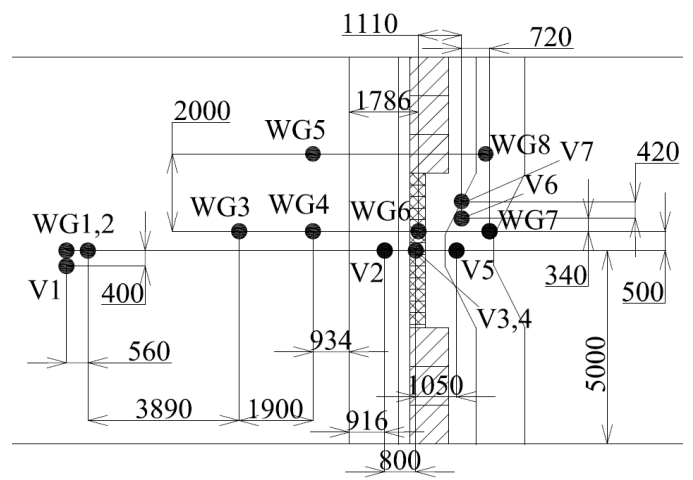

Figure 3. Locations of Capacity-type Wave Gauges (WG1-WG8) and Velocimeters (V1-V7) (unit: mm).

Table 2 shows the installation heights for electromagnetic velocimeters V1 through V7 and the types of tests in which measurements are conducted.

\begin{tabular}{|c|c|}
\hline \multicolumn{2}{|l|}{ Table 2. Installation Height of Electromagnetic Velocimeters } \\
\hline Velocimeter & \multicolumn{1}{c|}{ Installation Height } \\
\hline V1 & $65 \mathrm{~cm}$ from bottom of flume \\
\hline V2 & $20 \mathrm{~cm}$ from top of mound \\
\hline V3 & $9 \mathrm{~cm}$ from top of submerged breakwater \\
\hline V4 & $18 \mathrm{~cm}$ from top of submerged breakwater \\
\hline V5 & $20 \mathrm{~cm}$ from top of mound \\
\hline V6 & $20 \mathrm{~cm}$ from top of mound \\
\hline V7 & $5,15,20,30,40,50,60 \mathrm{~cm}$ from top of mound \\
\hline
\end{tabular}

The following two tests were conducted.

a) Measurement of the flow field in the vicinity of the mouth area and the pressure acting on the submerged breakwater

b) Sliding stability of the submerged breakwater against the flow.

In Test a), the flow velocity, water level, and pressure acting on the submerged breakwater is measured to validate the flow field calculations obtained from the CS3D. The pressures acting on the submerged breakwaters are measured using pressure gauges installed on a submerged acrylic breakwater model. A single submerged breakwater model for pressure measurement is installed at the center of the mouth opening, whereas 12 others are composed of concrete. Six pressure gauges are installed on the models $\mathrm{AD}$ and $\mathrm{AD} 2$, eight on the model $\mathrm{BE}$, and 12 on the model $\mathrm{CF}$. As shown in Fig. 4, the gauges are installed on the top and bottom faces and on the sides facing parallel to the shoreline. The sampling frequency is set at $500 \mathrm{~Hz}$.

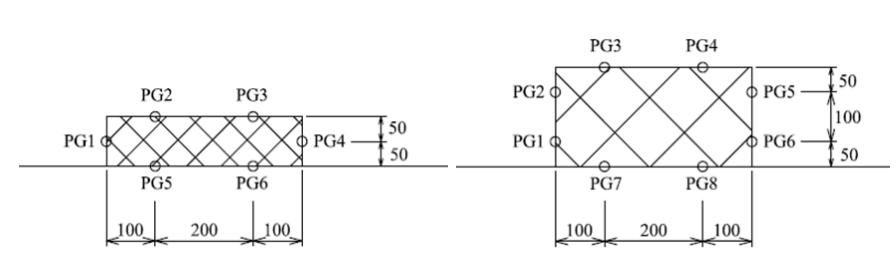

(1) AD, AD2

(2) BE

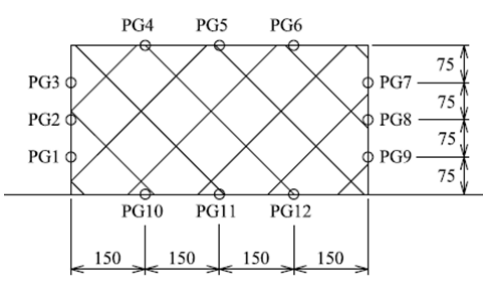

(3) $\mathrm{CF}$

Figure 4. Location of Pressure Gauges on Submerged Breakwater (unit: $\mathrm{mm}$ ).

In Test b), the velocity at the mouth area is gradually increased, and the sliding of the submerged breakwaters, which are composed of concrete, is monitored in order to validate the sliding stability obtained from the CS3D.

In the experiment, a steady flow is generated by axial flow pumps running at $25-70 \%$ of the rated output. The relationship between the pump output and flow velocity at the mouth area is shown in Table 3. As described in Fig. 3, the flow velocity at the mouth area is represented by the x-direction average flow velocity at a steady state measured $9 \mathrm{~cm}$ above the top face of the submerged breakwater located at the middle of the mouth opening, as measured by an electromagnetic flow velocimeter (V3). The initial depth for the experiment is $1.33 \mathrm{~m}$ measured from the floor of the flume. 


\begin{tabular}{|c|c|c|c|c|}
\hline \multicolumn{5}{|c|}{ Table 3. Flow Conditions of Experiments } \\
\hline & \multicolumn{4}{|c|}{ Flow Velocity at the Mouth [cm/s] } \\
\hline Pump Output & AD & BE & CF & AD2 \\
\hline $25 \%$ & - & 66.3 & - & - \\
\hline $30 \%$ & 70.5 & 81.9 & 105.6 & 71.5 \\
\hline $40 \%$ & 93.5 & 122.2 & 137.7 & 95.0 \\
\hline $50 \%$ & 121.8 & 153.8 & 159.5 & 126.5 \\
\hline $60 \%$ & 150.0 & 186.2 & 176.1 & 151.3 \\
\hline $70 \%$ & - & 207.0 & - & - \\
\hline$\%$ & 187.9 & - & - & - \\
\hline Regular wave with height $20 \mathrm{~cm}$ and 20 s cycle is generated. Maximum velocity is listed. \\
\hline \multicolumn{4}{|l|}{}
\end{tabular}

\section{Calculation Conditions}

The CS3D used for replication can perform calculations of complex water surface deformations such as breaking or overtopping waves. In addition, it can calculate the wave forces acting on a complicated geometry caisson, such as those on a slit-type structure, as well as the flow velocity inside the blocks and mounds. The CS3D employs the VOF method as a free-surface analysis model. Moreover, the continuity equation for a three-dimensional inviscid incompressible fluid and the Navier-Stokes equation, both expanded for porous models, are used as the basic governing equations. The calculation domain is enclosed by the heavy lines shown in Fig. 1, while the length of the domain and the grid size are shown in Table 4.

\begin{tabular}{|c|c|c|c|}
\hline & Length [m] & Grid Size [m] & Grid Number \\
\hline$x$-direction & 19.00 & $\begin{array}{r}0.05 \\
\end{array}$ & 380 \\
\hline$y$-direction & 10.00 & 0.05 & 200 \\
\hline$z$-direction & 2.50 & 0.05 & 50 \\
\hline \multicolumn{4}{|c|}{ Total Number of Grids } \\
\hline
\end{tabular}

The inflow and outflow boundary conditions are determined on the basis of the flow velocity at V3 and the water level at WG6, described in Fig. 3. The flow velocity boundary conditions for the inflow and outflow are shown in Table 5. For the inflow boundary condition, a constant flow velocity of $1 / 2$ of $v_{\text {in }}$ is given for $2.5 \mathrm{~s}$ from the beginning of the calculation. Flow velocity is then increased at a constant rate from 2.5 to $5.0 \mathrm{~s}$ in the calculation. From $5.0 \mathrm{~s}$ to the end of the calculation, the inflow velocity is kept constant at $v_{i n}$. The flow velocity is uniform for the entire boundary face. An example of the inflow boundary velocity time series is presented in Fig. 5. (the submerged breakwater model BE is used at a $50 \%$ pump output). For the outflow boundary, a constant velocity of $v_{\text {out }}$ is uniformly applied to the entire boundary face from the beginning to the end of the calculation.

\begin{tabular}{|c|c|c|c|c|c|c|c|c|}
\hline \multicolumn{7}{|c|}{ Table 5. Flow Velocity Boundary Conditions } \\
\hline & \multicolumn{2}{|c|}{ AD } & \multicolumn{2}{c|}{ BE } & \multicolumn{2}{c|}{ CF } & \multicolumn{2}{c|}{ AD2 } \\
\hline Pump Output & $v_{\text {in }}$ & $v_{\text {out }}$ & $v_{\text {in }}$ & $v_{\text {out }}$ & $v_{\text {in }}$ & $v_{\text {out }}$ & $v_{\text {in }}$ & $v_{\text {out }}$ \\
\hline $25 \%$ & - & - & 12.8 & 13.0 & - & - & - & - \\
\hline $30 \%$ & 15.0 & 15.1 & 13.5 & 13.7 & 13.7 & 17.7 & 13.5 & 13.5 \\
\hline $40 \%$ & 18.3 & 18.6 & 18.5 & 19.0 & 17.8 & 18.7 & 16.3 & 16.5 \\
\hline $50 \%$ & 24.3 & 24.9 & 21.0 & 22.0 & 21.5 & 23.2 & 22.1 & 22.6 \\
\hline $60 \%$ & 28.7 & 30.0 & 27.0 & 29.0 & 32.5 & 39.0 & 26.5 & 27.4 \\
\hline $70 \%$ & - & - & 32.7 & 37.0 & - & - & - & - \\
\hline
\end{tabular}

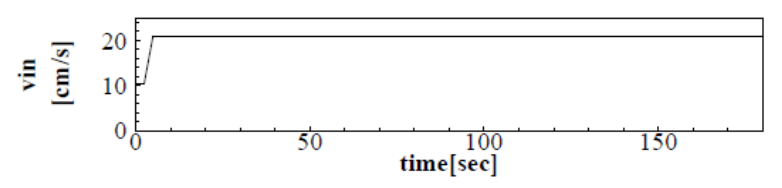

Figure 5. Example of Inflow Boundary Flow Velocity Time Series (BE, Pump Output: 50\%).

\section{COMPARISON BETWEEN CALCULATED AND EXPERIMENTAL RESULTS}

\section{Time Series Comparison}

At first, time series comparison of the sample case, which is used by the submerged breakwater model BE with a $50 \%$ pump output. Fig. 6 shows the flow velocity distribution on a plane $(\mathrm{z}=92.5$ 
$\mathrm{cm}$ ) calculated using the CS3D. $\mathrm{z}=92.5 \mathrm{~cm}$ equates to $9.2 \mathrm{~cm}$ above the top face of the submerged breakwater and is approximately the same height as the installation height of the electromagnetic velocimeter V3. One can observe that the flow is concentrated around the mouth opening and the flow velocity is high from the mouth opening to the mid-downstream region.

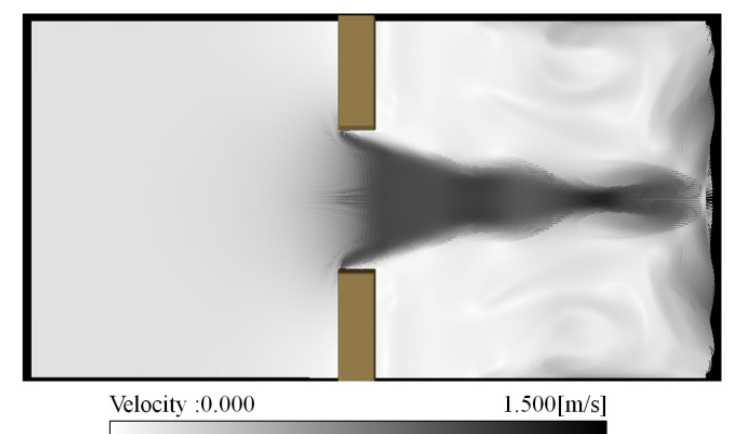

Figure 6. Planar Flow Velocity Distribution Calculated by the CS3D $(z=92.5 \mathrm{~cm})$.

Comparisons between the calculated and tested water level results for WG1-WG8 are shown in Fig. 7 the experimental results match well with the calculation results for a steady state condition at WG6, which is above the submerged breakwater. At WG1-WG5, which are located upstream of the mouth opening, the calculated results are $2-5 \mathrm{~cm}$ greater than the test results. At WG7 and WG8, which are downstream of the submerged breakwater and above the mound, the oscillation of the water level in the experiment is high. Overall, the calculated result is slightly smaller than the test result at WG7, whereas the two results match well at WG8.
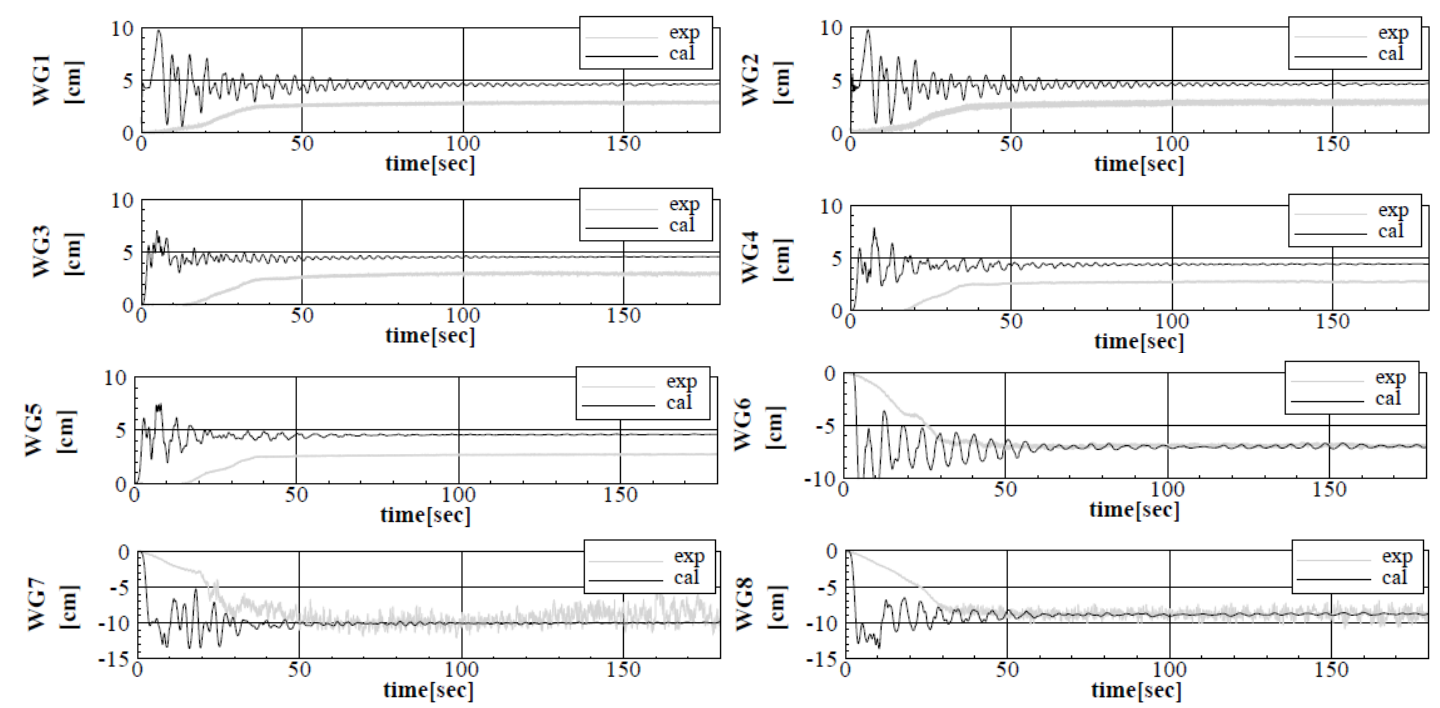

Figure 7. Time-series Comparison between Calculated and Experimental water levels.

Fig. 8 compares the calculated and experimental results for the flow velocity in the $\mathrm{x}$ direction at $\mathrm{V} 1$ through V7 in time series. The submerged breakwater model BE is used with a $50 \%$ pump output. V1 is a grid adjacent to the inflow boundary in the CS3D, and the calculation shows a higher velocity than the experimental results. The reason for this can be attributed to the fact that the flow velocity measured at $\mathrm{V} 1$, which is at a height of $65 \mathrm{~cm}$ above the bottom face, is smaller than that averaged in the vertical direction at point V1. By applying a flow velocity that is $20-30 \%$ higher than that measured at V1 as the inflow boundary condition at V3, which is $9 \mathrm{~cm}$ above the top face of the submerged breakwater, the flow velocity obtained from the calculation matched that obtained in the experiment. At V2, which is upstream of the submerged breakwater, and at V3, which is $18 \mathrm{~cm}$ above the top face of the submerged breakwater, the steady state calculation results match well with the test results. At V5V7, which are downstream of the submerged breakwater, the disturbance in the flow velocity is high in the experimental results. When averaged, the calculation results match well with the test results at V5 and V7, whereas at V6, the calculation results are smaller than the test results. 

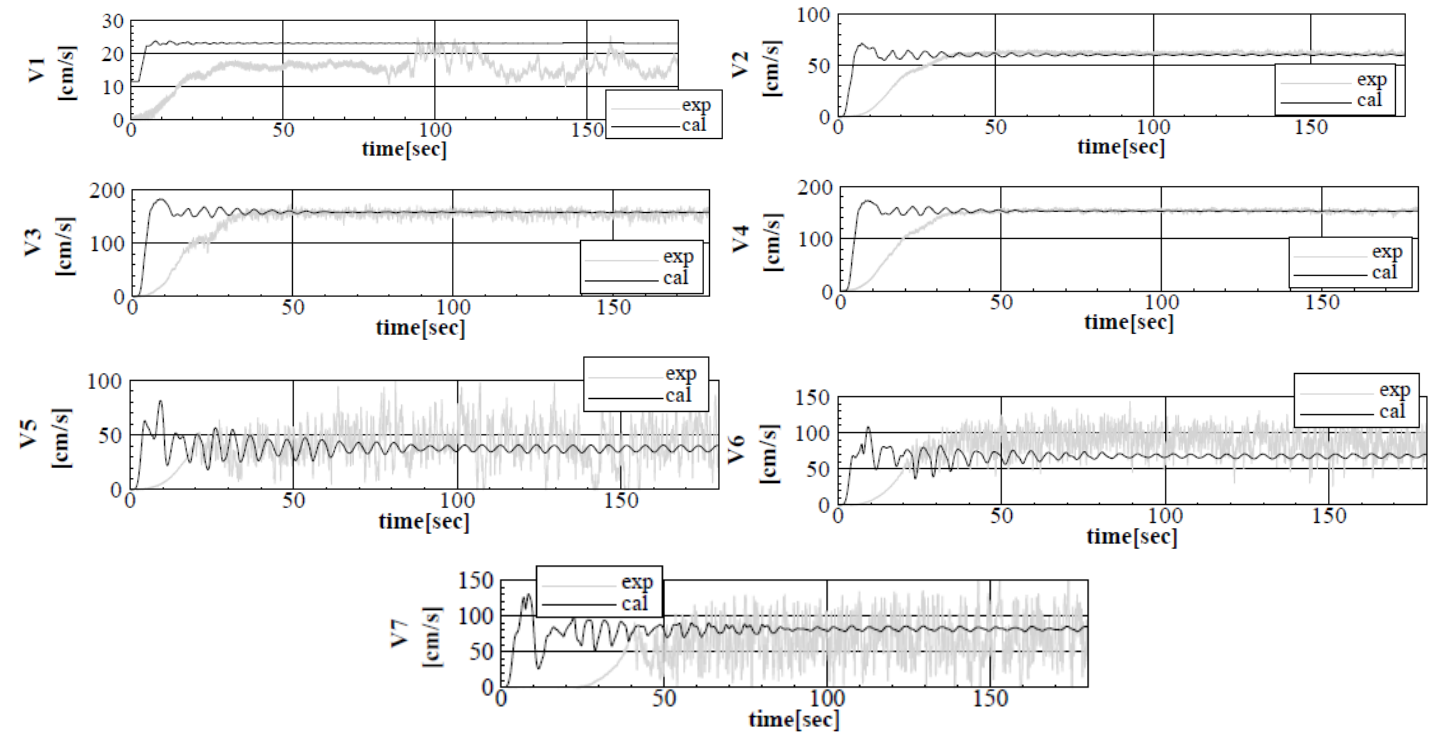

Figure 8. Time series comparison of $\mathrm{x}$-direction flow velocity between calculated and experimental results.

Fig. 9 shows a time series comparison of the calculated and tested pressure for the submerged breakwater model $\mathrm{BE}$ at a $50 \%$ pump output. The pressure oscillation is large in the experiments at PG1 and PG2, which are upstream of the submerged breakwater, and PG4, which is on the top face of the submerged breakwater. Overall, one can see that in the calculation, the upstream side shows values about $0.1 \mathrm{kN} / \mathrm{m}^{2}$ greater than those in the experiment, whereas at PG2 (the other upstream side), PG3 and PG4 (top face of the submerged breakwater), and PG5 and PG6 (downstream side), the steady state pressure is well replicated in the numerical calculation. At PG7 and PG8 on the bottom side, the calculated results are about $0.1-0.2 \mathrm{kN} / \mathrm{m}^{2}$ smaller than the experimental results.
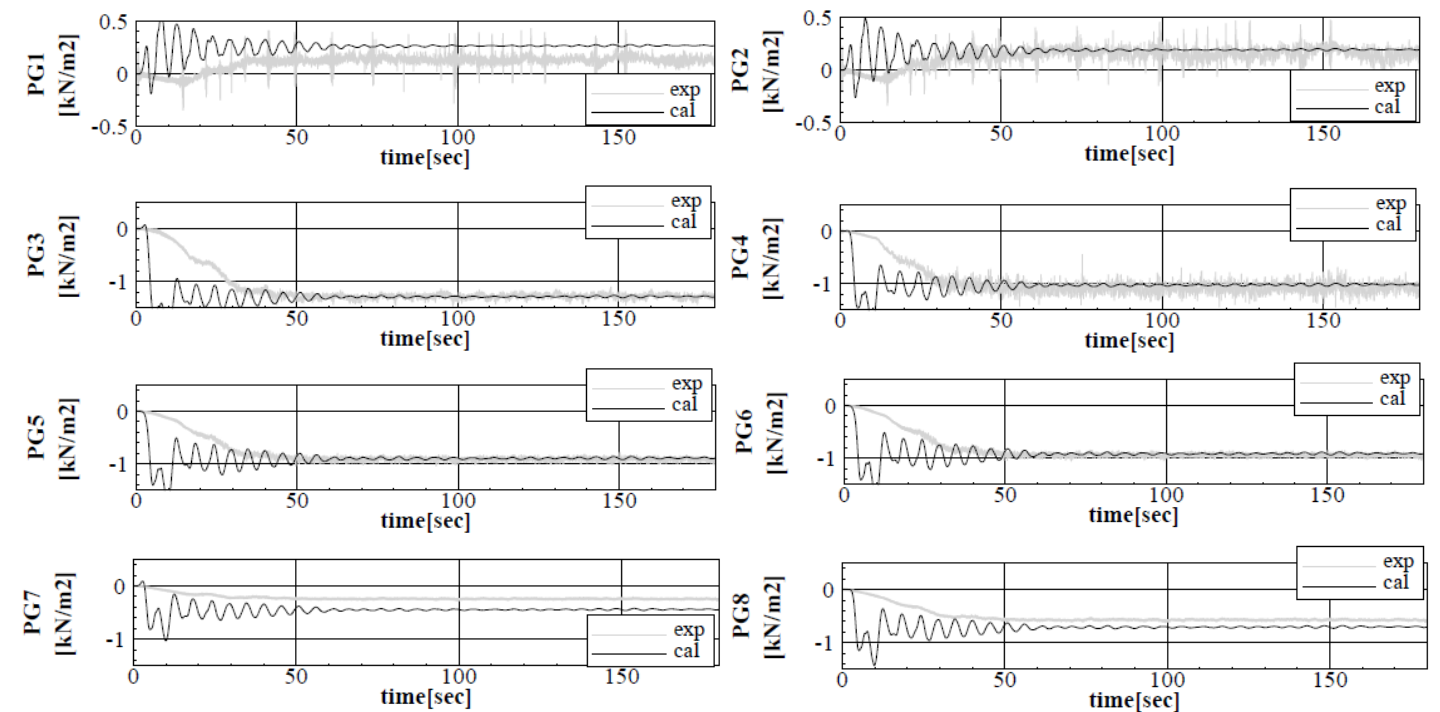

Figure 9. Time-series comparison between calculated and experimental pressure values.

\section{Average Value Comparison}

The flow velocity, water level, and pressure acting on the submerged breakwaters simulated in the CS3D were compared against the values obtained from the experiment in order to understand the trend of the CS3D results in relation to the differences in the submerged breakwater models and pump output percentage. The time-averaged values for the range 120 to $180 \mathrm{~s}$, which is a steady state measured in the region above the mound, are compared.

Fig. 10 shows a comparison between the calculated and test results for the vertical distribution of the $\mathrm{x}$-direction flow velocity at V7. The flow velocity is averaged for a 120 to $180 \mathrm{~s}$ time frame where the flow velocity is stable. The submerged breakwater model BE is used with a $50 \%$ pump output. In the upper layer, which is $60 \mathrm{~cm}$ in height, the calculation results become smaller than the test results, but the test results are well replicated in the numerical calculations in the lower to middle layers. 


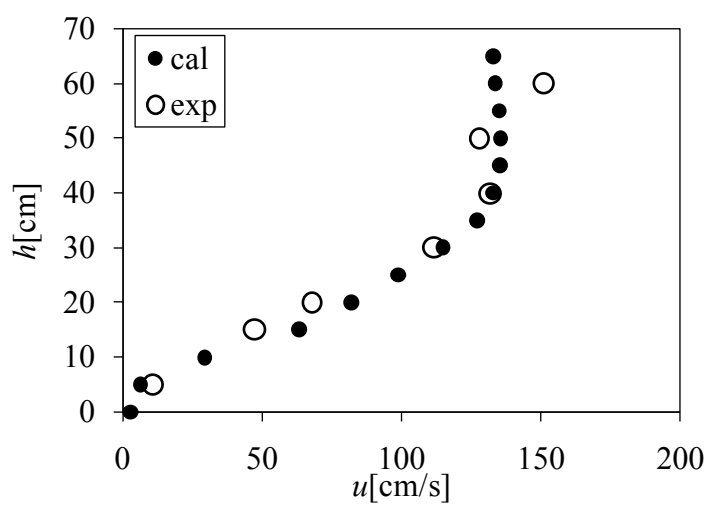

Figure 10. Vertical Distribution of the x-component of Flow Velocity at V7.

Fig. 11(left side) shows a comparison between the calculated and test results for the average flow velocity at $\mathrm{V} 3$, which is $9 \mathrm{~cm}$ above the top face of the submerged breakwater. The calculated results are slightly greater for $\mathrm{CF} 40 \%$ and $\mathrm{CF} 60 \%$, but for all other cases, by inputting the boundary conditions listed in Table 5, the calculated results match well with the test results. Fig. 11(right side) compares the calculated and test results for the average flow velocity at $\mathrm{V} 4$, which is $18 \mathrm{~cm}$ above the top face of the submerged breakwater. The dotted lines in the figure represent $20 \%$ deviation from the experimental results.
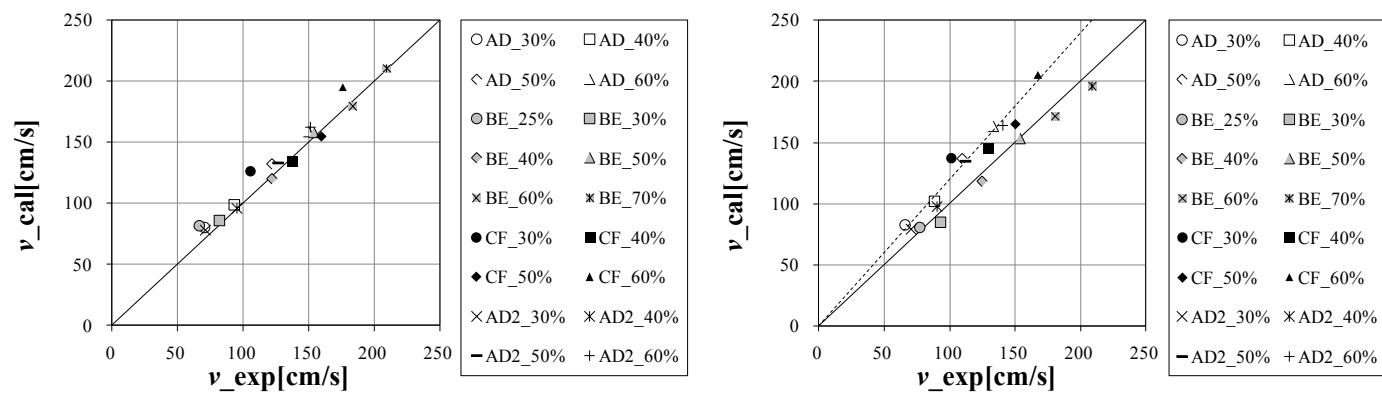

Figure 11. Comparison of Average Velocity at V3 (left) and V4 (right).

Fig. 12(left side) shows a comparison between the calculated and test results for the average water level at WG6, located above the top face of the submerged breakwater. However, the water level could not be replicated for the CF60\% case. Fig. 12(right side) shows a comparison between the calculated and test results for the average water levels at WG7. The calculated results match well with the test results when the drop in water level is small, but the water level could differ by a factor of two in cases where the drop in water level is large. Note that for WG7 in the CF60\% case, the points are plotted outside the graph owing to large deviations.
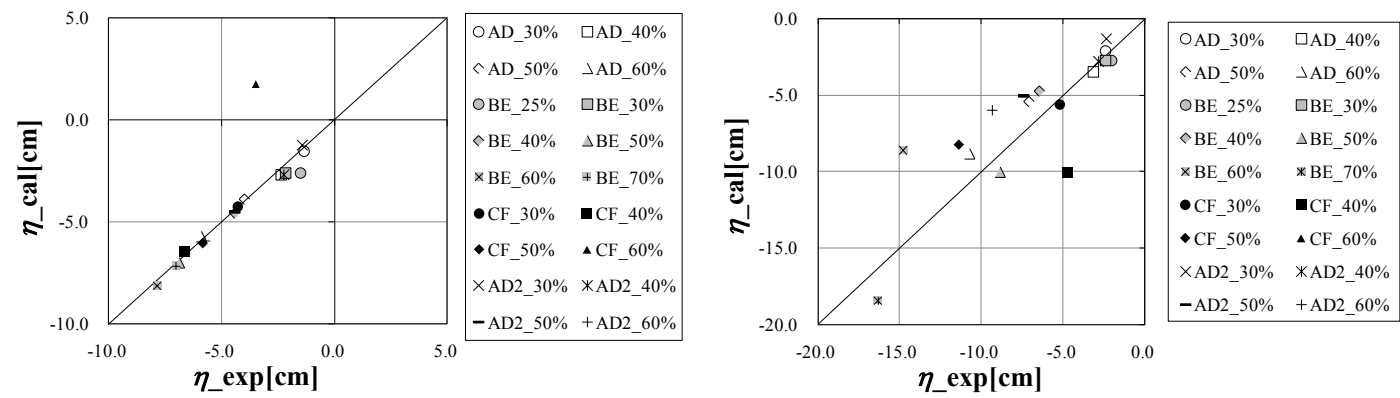

Figure 12. Comparison of Average Water Level at WG6 (left) and WG7 (right).

Fig. 13 (a) shows a comparison between the calculated and experimental results for the average pressure acting on the submerged breakwater model AD. The dotted lines show $20 \%$ deviation from the test results, and cases with pump outputs of $30 \%, 40 \%, 50 \%$, and $60 \%$ are shown. At the upstream side point PG1 and the bottom face points PG5 and PG6, several cases are seen where the calculated average pressure is too high. At the top face points PG2 and PG3 and downstream side point PG4, the calculated results are within $20 \%$ deviation from the test results.

Fig. 13(b) shows a comparison for the model AD2. The dotted lines show $20 \%$ deviation and 
comparisons are made for cases with pump outputs of $30 \%, 40 \%, 50 \%$, and $60 \%$. In most cases, the calculated results replicate values within $20 \%$ deviation from the experimental results.

Fig. 13(c) shows a comparison for the model BE. The dotted lines show $20 \%$ deviation from the test results, and cases with pump outputs of $25 \%, 30 \%, 40 \%$, and $50 \%$ are compared. At the upstream side points PG1 and PG2, there is a variation in the correlation of the average pressure. At the top face points PG3 and PG4, the calculated results vary from the test results where the absolute value of the negative pressure is small, but in other areas, the average pressure is replicated within $20 \%$ deviation from the test results. At the downstream side points PG5 and PG6, the calculated results vary from the test results where the absolute value of the negative pressure is small, but for most other cases, the calculated results match the experimental results. For the bottom face point PG7, the calculated results exceed $20 \%$ deviation from the test results, whereas at the bottom face point PG8, the calculated results show about $20 \%$ deviation from the test results in most cases.

Fig. 13(d) shows a comparison for the model CF. The dotted lines show $20 \%$ deviation from the test results and cases with pump outputs of $30 \%, 40 \%, 50 \%$, and $60 \%$ are shown. At the upstream side points PG1, PG2, PG3 and top face points PG4, PG5, PG6, the deviation from the test results is more than $20 \%$ in most cases. At the downstream side points PG7, PG8, PG9 and the bottom face points PG11 and PG12 (not including PG10), the deviation of the calculated results are within $20 \%$ of the test results. However at PG10, in most cases, the deviation from the test results is in excess of $20 \%$.

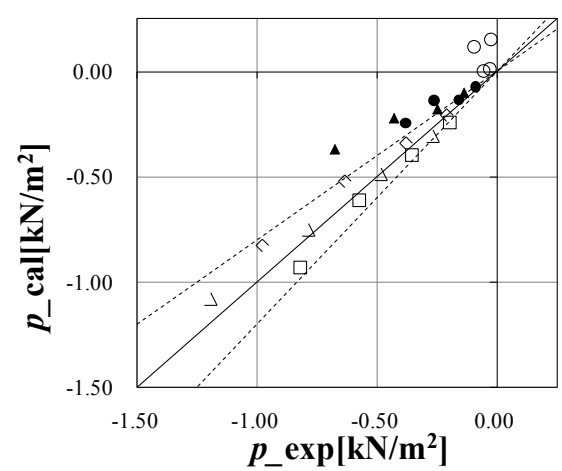

(a) $\mathrm{AD}$
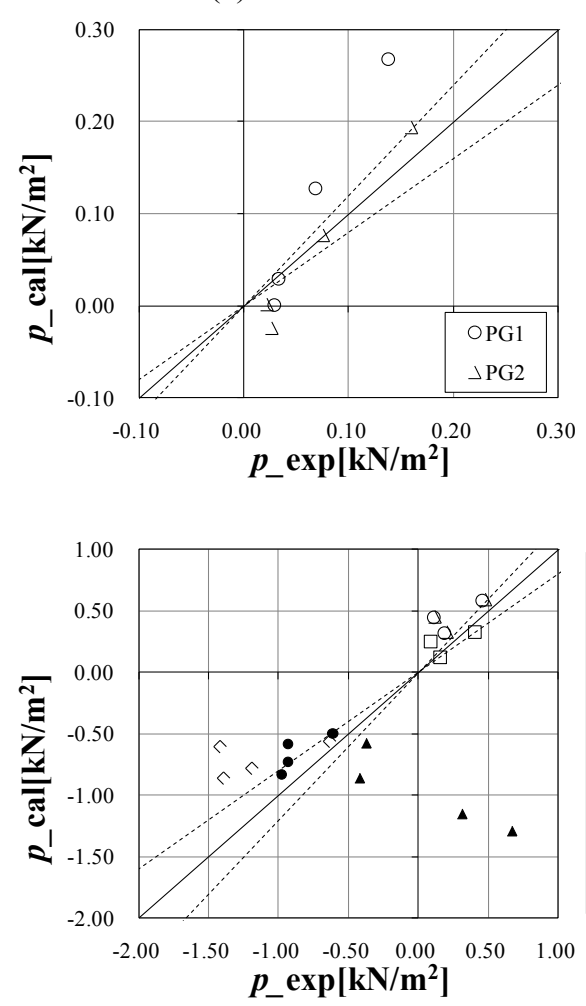

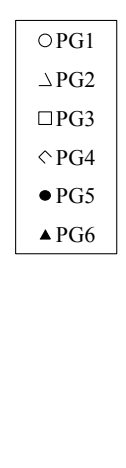

(c)

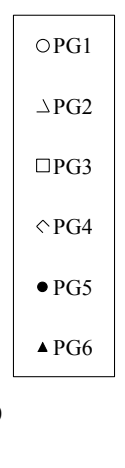

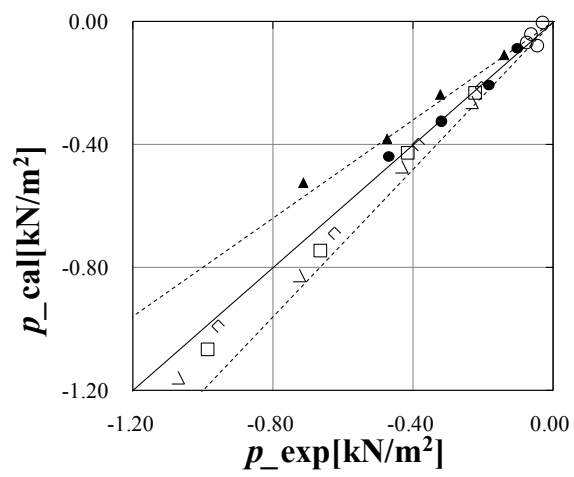

(b) $\mathrm{AD} 2$

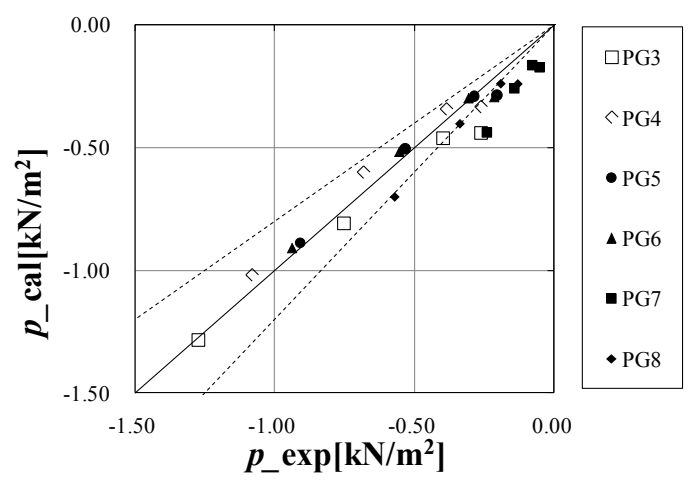

$\mathrm{BE}$

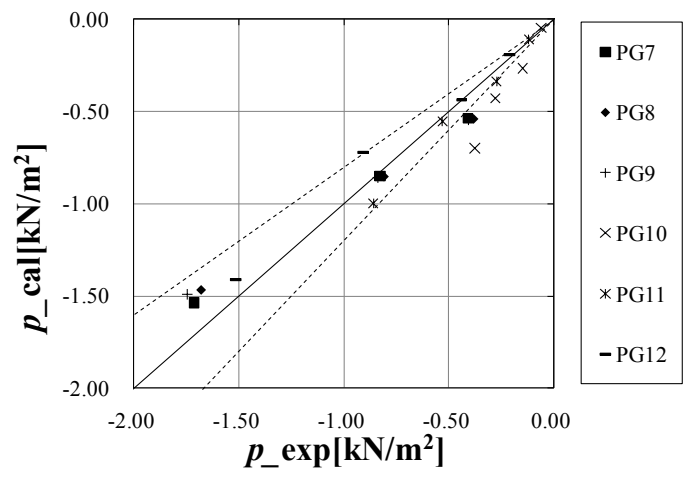

(d) $\quad \mathrm{CF}$

Figure 13. Comparison of Average Pressure. 
In this section, the flow velocity and the water level and pressure obtained from the CS3D are examined in time series and as averages in order to check how well they replicate the test results. It was confirmed that the flow velocity in the vicinity of the mouth opening and the water level obtained from the CS3D replicated within 20\% deviation with exceptions in certain cases and at certain measurement points. In addition, the reproducibility of the pressure values at the measurement points on a submerged breakwater varied depending on the dimensions of the submerged breakwater and point location.

\section{FLUID FORCES ON SUBMERGED BREAKWATERS AND SLIDING STABILITY}

In this section, the horizontal and vertical force acting on the submerged breakwaters are calculated on the basis of the CS3D results and compared with experimental results. Sliding stability is evaluated using the CS3D, and the validity is confirmed using the sliding test results for a submerged breakwater.

\section{Calculation Methods for Fluid Dynamic Forces Acting on Submerged Breakwaters}

To ascertain the sliding stability of a submerged breakwater, the fluid dynamic forces acting on it must be calculated. The horizontal pressure $f_{H}$ and vertical pressure $f_{V}$ acting on the submerged breakwater model BE in a steady flow are calculated by Eq. (1) using the pressure at each measuring point located on the model.

$$
f_{H}=\frac{\sum_{i=1}^{2} p_{i} S_{i}-\sum_{i=5}^{6} p_{i} S_{i}}{A_{H}}, f_{V}=\frac{-\sum_{i=3}^{4} p_{i} S_{i}+\sum_{i=7}^{8} p_{i} S_{i}}{A_{V}}
$$

Here $p_{i}$ is the average pressure in a steady state condition measured at pressure gauges PGi $(i=1,2$, ...8); $S_{i}$ is a characteristic area of the pressure gauge PG $i$, as shown in Fig. 14(a); $A_{H}$ and $A_{V}$ are the projected areas of the submerged breakwater model in the horizontal and vertical directions, respectively. In the $\mathrm{CS} 3 \mathrm{D}$, the horizontal pressure $\mathrm{fH}$ and vertical pressure $\mathrm{fV}$ acting on the submerged breakwater model BE are calculated according to Eq. (2) using average pressure values calculated for porous cells surrounding the submerged breakwater, as shown in Fig. 14(b).

$$
f_{H}=\frac{\sum_{i=1}^{5} p_{i}^{\prime} S_{i}^{\prime}-\sum_{i=13}^{17} p_{i}^{\prime} S_{i}^{\prime}}{A_{H}}, f_{V}=\frac{\sum_{i=5}^{13} p_{i}^{\prime} S_{i}^{\prime}-\left(\sum_{i=17}^{24} p_{i}^{\prime} S_{i}^{\prime}+p_{1}^{\prime} S_{1}^{\prime}\right)}{A_{V}}
$$

Here $p_{i}{ }^{\prime}$ is the average pressure value in a steady state condition calculated for the porous cells surrounding the submerged breakwater shown in Fig 14(b) and $S_{i}$ ' is a characteristic area of the cell. The horizontal pressure $f_{H}$ and lifting pressure $f_{V}$ are calculated in a similar manner for the submerged breakwater models $\mathrm{AD}, \mathrm{CF}$, and $\mathrm{AD} 2$ depending on the number of pressure gauges and cell counts.

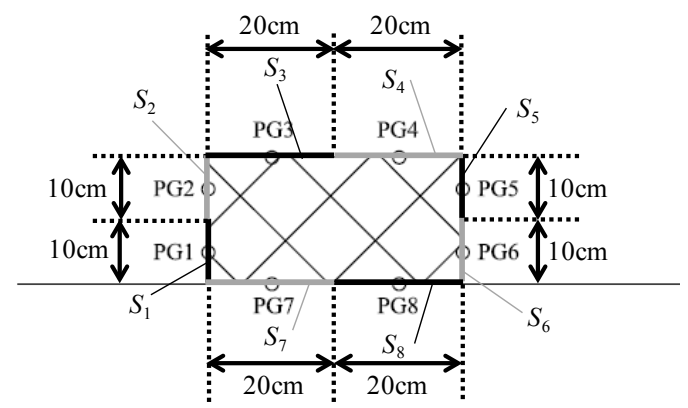

(a) Experiment

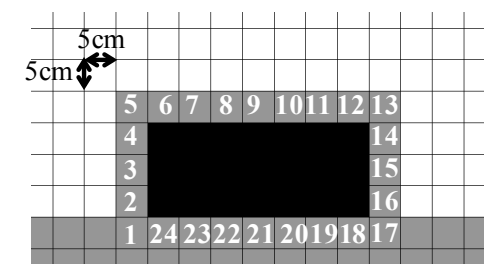

White: Fluid cell, black: Obstacle cell, gray: Porous cell

(b) CS3D

Figure 14. Characteristic area for pressure (submerged breakwater BE).

\section{Comparison between Calculated and Test Results}

Fig. 15 shows a comparison between the calculated and test results for the horizontal pressure $f_{H}$ and the vertical pressure $f_{V}$ acting on submerged breakwaters in all cases.

The dotted lines in the figure for $f_{H}$ represent $10 \%$ deviation from the test results. In the case of $\mathrm{CF} 30 \%$, the calculated results are twice the test results, but in all other cases, the calculated results match well with the test results. It can be seen that the horizontal pressure can be replicated with a maximum deviation of $10 \%$ from the test results.

The black dotted lines in the figure for $f_{V}$ represent 30\% deviation from the test results, and the gray dotted lines represent $15 \%$ deviation. The tendency observed here is that in the cases of $\mathrm{AD}$ and $\mathrm{AD} 2$, the calculated results are about $15 \%$ too large and in the case of BE, they are about $30 \%$ too small. In the case of $\mathrm{CF}$, the correlation varies. 
In the comparison of $\mathrm{CF} 60 \%$, the deviation is large and hence the points are plotted outside the graph.
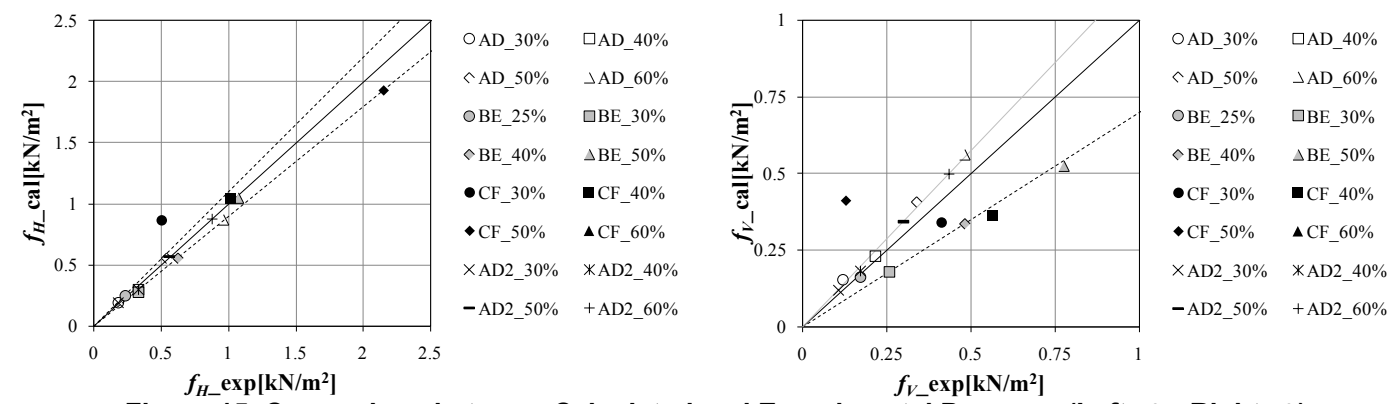

Figure 15. Comparison between Calculated and Experimental Pressure (Left: $f_{H}$, Right: $f_{V}$ ).

\section{Evaluation of Sliding Stability Using a Numerical Wave Flume}

All submerged breakwater sliding stability experiments in test b) are conducted using concrete models with the three weights (AD, BE, CF). $180 \mathrm{~s}$ of steady flow is generated for each pump output, starting from the smallest output to observe the change in a submerged breakwater. In the AD model test, wave generation is also conducted. The observation results for the submerged breakwater models $\mathrm{AD}, \mathrm{BE}$, and $\mathrm{CF}$ are shown in Table 6.

\begin{tabular}{|c|c|c|c|c|c|c|}
\hline \multicolumn{7}{|c|}{ Table 6. Flow Velocity Boundary Conditions } \\
\hline & \multicolumn{2}{|c|}{$\mathrm{AD}$} & \multicolumn{2}{|c|}{$\mathrm{BE}$} & \multicolumn{2}{|c|}{ CF } \\
\hline $\begin{array}{l}\text { Pump } \\
\text { Output }\end{array}$ & V3 $[\mathrm{cm} / \mathrm{s}]$ & Result & V3 $[\mathrm{cm} / \mathrm{s}]$ & Result & V3 $[\mathrm{cm} / \mathrm{s}]$ & Result \\
\hline $25 \%$ & - & - & 65.6 & No sliding & - & - \\
\hline $30 \%$ & 70.0 & No sliding & 83.7 & No sliding & 105.6 & No sliding \\
\hline $40 \%$ & 93.2 & No sliding & 123.0 & No sliding & 137.7 & No sliding \\
\hline $50 \%$ & 121.3 & No sliding & 154.7 & No sliding & 159.5 & No sliding \\
\hline $60 \%$ & 150.2 & No sliding & 186.2 & Sliding & 176.1 & No sliding \\
\hline $70 \%$ & - & - & 207.0 & Interlocked & - & - \\
\hline$※$ & 187.9 & Sliding & - & - & - & - \\
\hline
\end{tabular}

For $\mathrm{AD}$, sliding occurs for a regular wave with height $20 \mathrm{~cm}$ and cycle time $20 \mathrm{~s}$, and the flow velocity at V3 at that point is $187.9 \mathrm{~cm} / \mathrm{s}$. For BE, sliding occurs when the pump output is $60 \%$, and 13 submerged breakwaters started sliding in a fanned-out manner, thereby interfering with the adjacent submerged breakwaters. As the pump output is increased to $70 \%$, the submerged breakwaters interlock and do not slide. For the CF test, the pump output is increased to $60 \%$ and the flow velocity at V3 is increased to $176.1 \mathrm{~cm} / \mathrm{s}$; however, the submerged breakwater models did not start sliding.

In general, the following relationships represent the sliding condition;

$$
\begin{aligned}
& F_{H}+\mu F_{V}=\mu W^{\prime} \\
& F_{H}=f_{H} A_{H}, F_{V}=f_{V} A_{V}
\end{aligned}
$$

Here $F_{H}$ and $F_{V}$ are the horizontal and vertical forces; $\mu$ is the friction coefficient $(=0.6)$ between the concrete and rubble mound, and $W^{\prime}$ is the immersed apparent weight. Using the CS3D, the flow field is simulated and the forces acting on a submerged breakwater located at the middle of the mouth opening are calculated using Eqs. (2) and (3) to ascertain the sliding stability. The sliding safety factor formula shown in (4) is used to evaluate sliding stability and is derived from the sliding limit Eq. (3).

$$
S . F .=\frac{\mu\left(W^{\prime}-F_{V}\right)}{F_{H}}
$$

Here S.F. is the sliding safety factor. This shows that when S.F. $>1.0$, sliding will not occur, and when S.F. $<1.0$, sliding will occur.

Fig. 16 shows the relationship between the sliding safety factor obtained from the test results and the flow velocity obtained using the CS3D to simulate cases in which the pump output is set at $30 \%, 40 \%$, $50 \%$, and $60 \%$ and the case of a steady flow where the flow velocity at V3 is $187.9 \mathrm{~cm} / \mathrm{s}$. The white squares in the figure represent the cases where the submerged breakwater model did not start to slide in the physical test, whereas the black square represents the case where they started to slide. The plotted circular points represent the relationship between the flow velocity measured at V3 in Test a) and the 
sliding safety factor calculated using the pressure measured at PG1 through PG6 and feeding them into Eqs. (1), (3), and (4). When a curve is fitted to the plotted circles, the exponential curve has the best fit, which is drawn as a solid curve. Table 7 . shows the test results and the flow velocity at V3 and the sliding safety factor calculated for the submerged breakwater model AD using the CS3D. The sliding safety factor calculated using the results from the CS3D shows a good match to the sliding safety factor exponential curve derived from the test results. When the submerged breakwater models do not slide in the experiment, the safety factor value in the test and in the simulation are either more than or equal to 1 , and one can assume that the behaviors of the submerged breakwater models are consistent with the sliding safety factor. When the case in which the submerged breakwaters started to slide is simulated in the CS3D, a safety factor of 0.89 is returned, which is smaller than 1.0 . From this, it can be said that the CS3D results can determine whether a submerged breakwater did slide in the test.

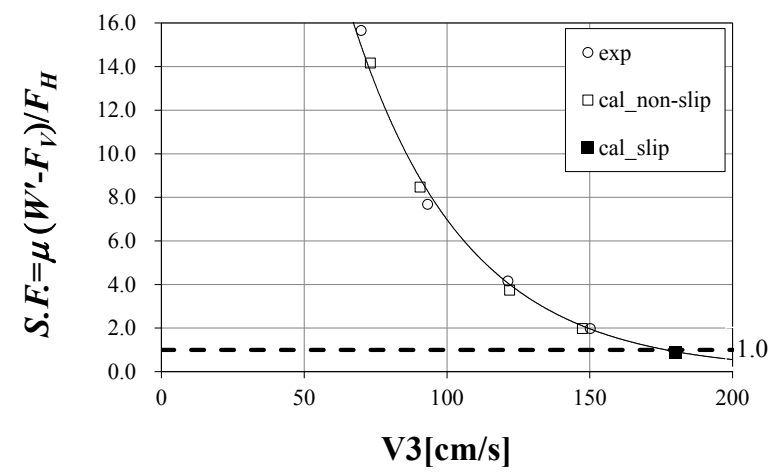

Figure 16. Relationship between Velocity at V3 and Sliding Safety Factor for the Model AD (solid curve: exponential curve fitted to exp.).

Table 7. Sliding Safety Factors Obtained from Tests and CS3D Simulation and Sliding Test Results (AD)

\begin{tabular}{|c|c|c|c|c|c|}
\hline \multirow{2}{*}{ Pump Output } & \multicolumn{3}{|c|}{ Experimental Results } & \multicolumn{2}{|r|}{ CS3D } \\
\hline & V3 $[\mathrm{cm} / \mathrm{s}]$ & Sliding Safety Factor & Behavior & V3 [cm/s] & Sliding Safety Factor \\
\hline $30 \%$ & 70.0 & 15.65 & No Slide & 79.8 & 14.16 \\
\hline $40 \%$ & 93.2 & 7.67 & No Slide & 98.7 & 8.46 \\
\hline $50 \%$ & 121.3 & 4.16 & No Slide & 132.1 & 3.74 \\
\hline $60 \%$ & 150.2 & 1.97 & No Slide & 158.7 & 1.97 \\
\hline$※$ & 187.9 & - & Slide & 192.4 & 0.89 \\
\hline
\end{tabular}

Fig. 17 shows the relationship between the velocity at V3 and the sliding safety factor. The square points show the relationship between the flow velocity simulated in the CS3D and the sliding safety factor calculated using the calculated velocity in the cases of pump outputs of $25 \%, 30 \%, 40 \%, 50 \%$, $60 \%$, and $70 \%$. The white squares show cases where the submerged breakwater models do not slide in the physical test, whereas the black squares represent cases where they start to slide. The circular points are also plotted and represent the relationship between the flow velocity measured at V3 in Test a) and the sliding safety factors calculated using the pressure measured at PG1 through PG8. The solid curve is an exponential curve fitted to the circular points, whereas the dotted curves show $20 \%$ deviation.

Table 8 shows the relationship between the flow velocity at V3 and the sliding safety factor for the submerged breakwater model BE obtained from the tests and the simulations using the CS3D. One can observe that the sliding safety factor calculated from the CS3D results match well with the $+20 \%$ exponential curve obtained from the test results. When the submerged breakwater models do not slide in the test, the sliding safety factor from the test and the simulation are both more than 1.0, and one can observe that the behavior of a submerged breakwater model is consistent with the sliding safety factor. However, in the case of a $60 \%$ pump output, when the submerged breakwater starts to slide, the safety factor calculated in the CS3D is 1.54 , which is greater than 1.0 , and thus, the CS3D cannot predict the sliding of the model. In the test, the flow velocity at V3 is $186.2 \mathrm{~cm} / \mathrm{s}$, whereas the CS3D simulation showed $179.3 \mathrm{~cm} / \mathrm{s}$. Thus, it is possible that the low velocity estimate in the CS3D led to the excessive estimate of the sliding stability.

Fig. 18 shows the simulated width-wise distribution of the sliding safety factor for the submerged breakwater model BE with a $60 \%$ pump output. The dotted line shows $20 \%$ deviation. Considering from Fig. 18 that the sliding safety factor calculated from the CS3D is 20\% smaller than that obtained from the test results, it can be assumed that the dotted curve in Fig. 18 represents the experimental 
sliding safety factor. In this case, the sliding safety factor for No. 1, which is close to the head, and for No. 13 is as low as 1.1, and it is possible that the sliding started at the submerged breakwaters closer to the head area. In the case of a $70 \%$ pump output, a submerged breakwater model does not slide although the sliding safety factor calculated from the CS3D is 0.92 , which is smaller than 1 . This is assumed to be because in this case, friction occurs not only between the bottom of the concrete and the rubble mound but also between the adjacent submerged breakwaters.

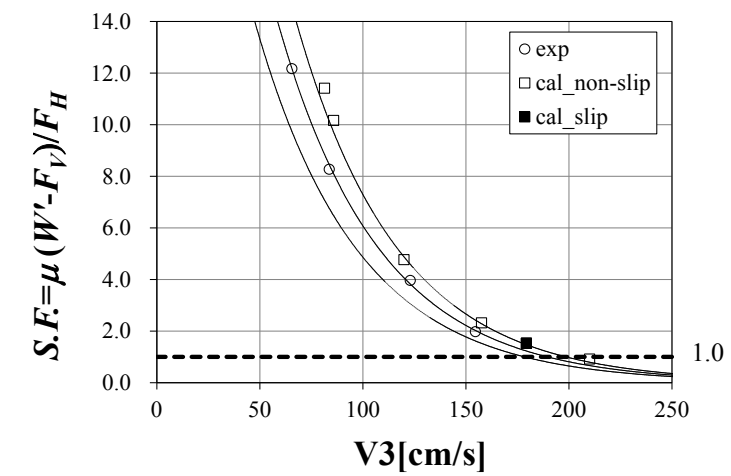

Figure 17. Relationship between Velocity at V3 and Sliding Safety Factor for the Model BE (solid curve: exponential curve fitted to exp., dotted curves: $\pm 20 \%$ deviation from the exponential curve).

Table 8. Sliding Safety Factors Obtained from Tests and CS3D Simulation and Sliding Test Results (BE)

\begin{tabular}{|c|c|c|c|c|c|}
\hline \multirow{2}{*}{ Pump Output } & \multicolumn{3}{|c|}{ Experimental Results } & \multicolumn{2}{c|}{ CS3D } \\
\cline { 2 - 6 } & V3 [cm/s] & Sliding Safety Factor & Behavior & V3 [cm/s] & Sliding Safety Factor \\
\hline $25 \%$ & 65.6 & 12.18 & No Slide & 81.4 & 11.42 \\
\hline $30 \%$ & 83.7 & 8.28 & No Slide & 85.9 & 10.17 \\
\hline $40 \%$ & 123.0 & 3.97 & No Slide & 119.9 & 4.77 \\
\hline $50 \%$ & 154.7 & 1.98 & No Slide & 157.6 & 2.32 \\
\hline $60 \%$ & 186.2 & - & Slide & 179.3 & 1.54 \\
\hline $70 \%$ & 207.0 & - & No Slide - Interlocked & 210.0 & 0.92 \\
\hline
\end{tabular}
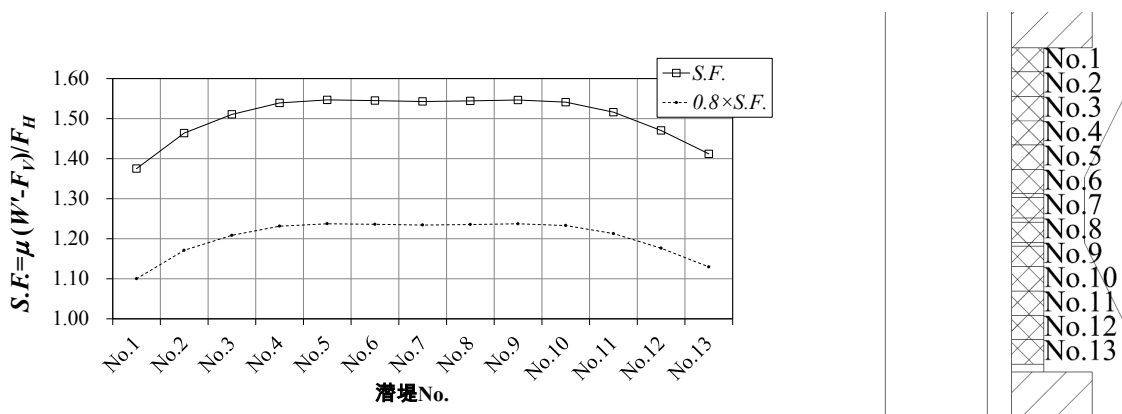

Figure 18. Width-wise Distribution of Sliding Safety Factor for Model BE per Simulation at a $60 \%$ pump output (dotted curve: $\mathbf{- 2 0} \%$ deviation, the right figure shows Submerged Breakwater Model Placement)

Fig. 19 shows the relationship between the flow velocity at V3 and the sliding safety factor for CF. The square points represent the relationship between the flow velocity and sliding safety factor as calculated in CS3D for pump outputs of 30, 40,50, and 60\%. The circular points are also plotted and they represent the relationship between the flow velocity measured at V3 in Test a) and the sliding safety factors calculated using the pressure measured at PG1 through PG12. The solid curve is an exponential curve fitted to the circular points. Table 9 shows the relationship between the flow velocity at V3 and the sliding safety factor, as obtained from the tests and CS3D simulation. The sliding safety factor calculated from the CS3D simulation matches well with the sliding safety factor exponential curve fitted to the test results. For tests with pump outputs of 30,40 , and $50 \%$, a submerged breakwater does not slide and the sliding safety factor from the test results and the simulation are both greater than or equal to 1 . Therefore, the behaviors of the submerged breakwater models are consistent with the sliding safety factor. Even in the cases where the submerged breakwater models do not slide, the safety factor obtained from the CS3D simulation is 0.87 with a pump output of $60 \%$, which is smaller than 1 . However, the velocity at V3 obtained from the CS3D is $195.0 \mathrm{~cm} / \mathrm{s}$ when the flow velocity at V3 obtained from the test is $174.9 \mathrm{~cm} / \mathrm{s}$. Therefore, it is assumed that the safety factor will drop below 1 in the cases where the flow velocity is $195.0 \mathrm{~cm} / \mathrm{s}$ in the exponential curve. Consequently, it is assumed 
that a submerged breakwater model could slide if a velocity in excess of $195.0 \mathrm{~cm} / \mathrm{s}$ is realized in an experiment.

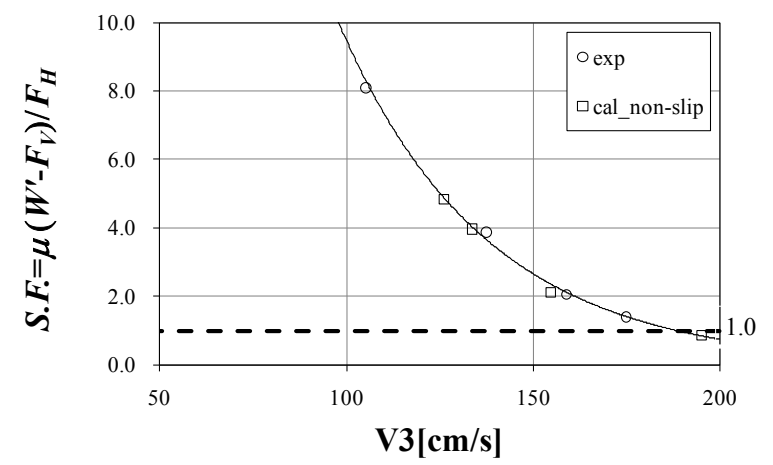

Figure 19. Relationship between Velocity at V3 and Sliding Safety Factor for the Model CF (solid curve: exponential curve fitted to exp.)

Table 9. Sliding Safety Factors Obtained from Tests and CS3D Simulation and Sliding Test Results (CF)

\begin{tabular}{c|c|c|c|c|c}
\hline \multirow{2}{*}{ Pump Output } & \multicolumn{3}{|c|}{ Experimental Results } & \multicolumn{2}{c}{ CS3D } \\
\cline { 2 - 5 } & V3 [cm/s] & Sliding Safety Factor & Behavior & V3 [cm/s] & Sliding Safety Factor \\
\hline $30 \%$ & 105.2 & 8.10 & No Slide & 126.1 & 4.83 \\
\hline $40 \%$ & 137.4 & 3.88 & No Slide & 133.7 & 3.97 \\
\hline $50 \%$ & 158.9 & 2.06 & No Slide & 154.6 & 2.13 \\
\hline $60 \%$ & 174.9 & 1.40 & No Slide & 195.0 & 0.87 \\
\hline
\end{tabular}

It is understood that the $\mathrm{CS} 3 \mathrm{D}$ can predict the horizontal pressure $f_{H}$ acting on a submerged breakwater within $10 \%$ accuracy from the test results, whereas the vertical pressure $f_{V}$ is predicted within $30 \%$ accuracy. If the CS3D can replicate the flow condition observed in the experiments, it can replicate the sliding safety factor obtained from the test results. It is also understood that when numerical calculation error is considered, the sliding of a submerged breakwater can be determined quite accurately.

\section{SUMMARY}

In this study, research into the stability of a breakwater at the mouth area of a port was conducted. The major findings are summarized below.

(1) It was confirmed that the flow velocity and water level in the vicinity of a breakwater mouth opening can be replicated within $20 \%$ deviation by using the CS3D. The pressure simulated at the measurement points on a submerged breakwater can replicate the pressure in some areas, and not in other areas.

(2) It was found that the CS3D can replicate the horizontal pressure $f_{H}$ acting on a submerged breakwater within $10 \%$ deviation from the experimental results and the vertical pressure $f_{V}$ within $30 \%$ accuracy compared with the experimental values. A sliding experiment validated the use of the CS3D to evaluate the sliding stability.

\section{REFERENCES}

Taro Arikawa, Fuminori Yamada, Mironu Akiyama (2005): Research on adaptability of threedimensional numerical wave flume to tsunami forces, Proceedings of Ocean Engineering, Vol. 52, pp. 46-50.

Toshio Iwasaki, Akira Mano, Takehiro Nakamura, Nobuyuki Horikoshi (1984): Research on steady flow fluid dynamic forces acting on submerged mound materials and pre-packed banks, Proceedings of Ocean Engineering, Vol. 31, pp. 527 - 531.

Katsutoshi Tanimoto, Katsutoshi Kimura, Keiji Miyazaki (1988): Experimental Research on the stability of submerged breakwaters at the opening mouth of tsunami breakwaters, Port and Airport Research Institute Report, Vol. 27 Issue 4, pp. 93-121. 